\title{
THE SHEAHAN-MDRU DIAMOND \& MANTLE ROCK LITERATURE SERVICE
}

\author{
Brigitte Petrie $^{1}$ and Patricia Sheahan ${ }^{2}$ \\ ${ }^{1}$ Mineral Deposit Research Unit, University of British Columbia; ${ }^{2}$ North York, Toronto
}

\section{DIAMOND \& MANTLE ROCK TECHNICAL LITERATURE}

\section{Usefulness \& importance}

As diamond exploration companies become increasingly proactive about the promotion of their projects, it is easy to become less than objective about how and where your (economic) research efforts are focused or exploration dollars are spent. Being well informed can not only lessen your bias toward hotly promoted areas, it helps you validate (or reject) ideas about the prospectivity of a particular area, exploration technique or new technology. Reading a broad range of technical literature not only increases your scientific 'knowledge', it lessens the potential for 'tunnel-vision' in a specialist field and keeps your mind open to alternative ways of looking at the same questions. In this way, being aware of current and historical technical literature can be your most cost-effective and important research or diamond exploration tool.

From a legal perspective, evidence of reliable reports of diamond occurrences or resource estimates are more significant these days with the technical reporting guidelines laid out in CIM reporting standards and NI 43-101.

At both a global and national level, federal and provincial governments are become increasingly proactive about attracting mineral exploration dollars. Geological surveys are doing more reconnaissance diamond exploration and data compilations to encourage companies to explore in their region. Taking advantage of good scientific research as soon as it becomes publically available has the potential to either save you doing it yourself or (for a newly discovered area) present a premium staking opportunity. A recent example is the Lac Bienville region in northern Quebec where chromium picroilmenites were reported during a collaborative esker sediment sampling program carried out by Natural Resouces Canada and the Ministere des Ressources Naturelles (see Parent, Beaumier and Paradis 2002). Using the literature as successfully as Dr. John Williamson did in the 1950's resulted in the discovery of the Mwadui pipe/mine in Tanzania (P. Sheahan - pers. comm.).

\section{Impact of the electronic age on technical research}

The Internet has revolutionized the way in which we search and research technical literature. Instant delivery time has allowed researchers to learn of new literature as soon as it is published from the comfort of an ergonomic chair. Or has it? Despite the obvious advantages, the Internet has also had a hugely negative impact on the technical research process. Firstly, it is easy to become complacent in reading and referencing only the literature which is accessible online. In fact it is estimated that 'only $8 \%$ of journals and a small fraction of books' are available online (Herring 2001) and of those, very few have any real technical substance. Secondly, there are millions of websites out there. Plug 'diamond' into a major search engine and you will get hits ranging from 'Black Diamond' video to 'Diamond Peak Ski Resort'. The web is an uncatalogued mess and despite what search engines claim to do, none of them searches the entire web (Weston 2002) nor do they know you are looking for gemstones not video players. Thirdly, many of these online publications (for whatever reason) can cease to be accessible or have not yet been digitized. It has been suggested that not much on the Internet is more than 15 years old (Herring 2001).

Bearing the Internet's limitations and assuming you are a consultant or company that considers technical literature an important research tool, you could potentially spend up to 60 hours per month not only surfing the net but reading table of contents pages, attending relevant conferences and scanning newly released books. For most already time-stretched geologists this isn't feasible. Access to literature is also a problem, especially for English-speaking geologists based in Non-English speaking countries or those spending extended periods in the field. In fact most geologists are trying to reduce the number of emails/websites/TOC pages they read. So how do you stay aware of and gain access to a broad range of print and electronic technical literature without spending too much time and money searching and researching it yourself?

\section{Maximizing the value of your technical literature}

Use the Sheahan-MDRU literature - we do the technical literature scanning, sorting and compilation on your behalf. We keep you informed of relevant literature 
and make it accessible as soon as it becomes available. After scanning over 200 specialist magazines, academic journals, conference proceedings, symposium volumes and special publications from all over the world, we compile and electronically distribute a list of $200-300$ references specific to diamond and mantle rock research each month. These references are then keyword-searchable through the Sheahan-MDRU website.

Each reference has been keyworded using descriptors which are tailored to diamond exploration and mantle rock research. The multiple keyword search tool allows you to find with ease information related to a particular topic of interest such as rock type, indicator mineral, geochemical signature, exploration area "hot spot" etc. Unlike most databases, any reference you find is available as a hardcopy.

\section{The Sheahan-MDRU Library}

In addition to the literature scanning service, we have the most comprehensive, publicly available technical library related to diamond exploration and mantle rock research in the world. Spanning a period of 100 years, the library includes out-of-print and historical material not available elsewhere thanks to the efforts of Patricia Sheahan with her lifetime passion for diamonds and their geological setting. Included in the collection are the historical George Kunz collection documenting diamond occurrences in Southern Africa and North America, the International Kimberlite Conference proceedings volumes and obscure specialist articles from Russian, South American, African, French and Indian publications. Papers are generally filed by author so it is easier to acquire previous papers and gain an appreciation of the author's thought process through time.

We know the importance of 'grey literature' to the diamond exploration community and as such we focus on scanning and including papers from conference/symposium proceedings, theses, technical industry news items, workshops etc. Many of these publications are one-offs and are increasingly difficult to source, especially with move toward 'virtual' libraries. Furthermore, those in-house libraries that still exist, often have incomplete collections or only source 'core' journals.

\section{Technical Consultation Services}

If you don't have the time or inclination to do your own literature search, we can do this on your behalf. Pat
Sheahan is still very much involved in a technical advisory capacity. With her 35 years experience as a diamond and mantle rock researcher, she has a unique perspective on the evolution of the literature in a particular area and an intimate knowledge of what's available, if you tell her what you hope to find.

The collection is housed at the Mineral Deposit Research Unit (MDRU) within the Department of Earth and Ocean Sciences at the University of British Columbia. MDRU is an internationally known research group devoted to solving mineral exploration-related problems and training students for employment in the industry. MDRU and the Earth and Ocean Sciences department are increasingly active in diamond and mantle rock research with graduate students involved in collaborative industry-funded projects. The department also employs one of the world's foremost diamond experts, Maya Kopylova, who oversees the recently established diamond exploration lab. As well as being able to utilize in-house expertise, the literature service is used by students, research associates and companies involved in MDRU projects. As such, we appreciate both the academic and industry perspective on how technical literature is used and accommodate both in service we provide.

For further information on the Sheahan-MDRU literature service, please go to our website at http://www.mdru.ubc.ca/sheahan_home1.htm or contact Brigitte Petrie at bpetrie@eos.ubc.ca.

\section{REFERENCES}

Herring, M 2001. 10 reasons why the Internet is no substitute for a library. Am. Libraries 32, 76-78.

Parent, M., Beaumier, M., Paradis, S.J. 2002. A new highpotential target for diamond exploration in northern Quebec - Chromium picroilmenites in esker sediments of the Lac Bienville (33 P) region. PRO 2002-03, Geologie Quebec report, pp. 1-4.

Weston, W. 2002. Access to scientific literature. Naure, vol. 420, 7 Nov., p. 19. 